\title{
Choosing between different Al approaches? The scientific benefits of the confrontation, and the new collaborative era between humans and machines
}

\author{
Jordi Vallverdú
}

Philosophy Department.

Universitat Autònoma de Barcelona

jordi.vallverdu@uab.es

\begin{abstract}
Al}$ is a multidisciplinary activity that involves specialists from several fields, and we can say that the aim of science, and $\mathrm{Al}$ science, is solving problems. Al and computer sciences are been creating a new kind of making science, that we can call in silico science. Both models top-eown and bottomup are useful for e-scientific research. There is no a real controversy between them. Besides, the extended mind model of human cognition, involves human-machine interactions. Huge amount of data requires new ways to make and organize scientific practices: supercomputers, grids, distributed computing, specific software and middleware and, basically, more efficient and visual ways to interact with information. This is one of the key points to understand contemporary relationships between humans and machines: usability of
\end{abstract}

scientific data.

Keywords: Al, e-Science, epistemology, grids, information.

Acknowledgement: I thank to all the attendants to the E-CAP 2005 Philosophy and Computing Congress for their comments, suggestions and critics to my initial ideas. My special gratitude to Dr. Floridi for his encouraging words and sharp suggestions. This research has been developed under the main activities of the TECNOCOG research group (UAB) about Cognition and Technological Environments, [HUM2005-01552], funded by MEC (Spain).

\section{Defining Artificial Intelligence (AI).}

Trying to find an answer about the meaning of $\mathrm{Al}$, we define at the same time our professional training and theoretical background. As philosopher of science and computing, I am profoundly interested on scientific reasoning and, without doubt, on artificial intelligence (Al) research topics. There is, or it can exist, a relationship between Al and rationality (it depends of our definition of 'rationality'), it seems not too clear for all those researchers involved in the development of Al. We use different meanings of 'intelligence' or 'rationality'.

Let me see a good definition of Al. According to Simon (1995): 95, "Al deals with some of the phenomena surrounding computers, hence is a part of computer science. It is also a part of psychology and cognitive science. It deals, in particular, with the phenomena that appear when computers perform tasks that, if performed by people, would be regarded as requiring intelligence-thinking". We should also consider what means 'intelligence'. Is chess playing an intelligent action? Is it also a rational activity to coordinate successfully six legs like an ant? For Al specialists, like Rodney Brooks, can exists 'intelligence

\footnotetext{
${ }^{1}$ Kurzweil (1990).
} 
without representation', or 'intelligence' can be something that elephants have (related to 'intelligence') although they don't play chess. We talk even about 'emotional intelligence'!

At the same time, Al is a multidisciplinary activity that involves specialists from several fields like neuroscience, psychology, linguistics, logic, robotics, computer sciences, mathematics, social sciences, biology, philosophy or software engineering. And it presents several interests such as intelligence, knowledge representation, creativity ${ }^{3}$, robotics, language translation, domotics, emotions, data mining, intentionality, consciousness or learning.

Perhaps the key definition is that of 'intelligence'. From Princeton web service ${ }^{4}$, it is described like "the ability to comprehend; to understand and profit from experience". And the Oxford English Dictionary says about intelligence "7a. Knowledge as to events, communicated by or obtained from one another; information, news, tidings, spec. information of military value... b. A piece of information or news... c. The obtaining of information; the agency for obtaining secret information; the staff of persons so employed, secret service... d. A department of a state organization or of a military or naval service whose object is to obtain information (esp. by means of secret service officers or a system of spies)". Both are interesting definitions of what is considered usually as intelligence. I prefer not to look at philosophical definitions because it would imply to forget the aim of this paper, that is, the relationships between humans and machines and the contributions to it from Al whatever means the ' $l$ ' of this controversial acronym.

\section{Historical precedents about critics about intelligent machines.}

Artificial intelligence or autonomous machines are something that both fascinate and worry human beings. We can travel to XVII ${ }^{\text {th }}$ Century and read in René Descarte's Discourse on Method (1637): "And here, in particular, I stopped to reveal that if there were machines which had the organs and the external shape of a monkey or of some other animal without reason, we would have no way of recognizing that they were not exactly the same nature as the animals; whereas, if there was a machine shaped like our bodies which imitated our actions as much as is morally possible, we would always have two very certain ways of recognizing that they were not, for all their resemblance, true human beings. The first of these is that they would never be able to use words or other signs to make words as we do to declare our thoughts to others: for one can easily imagine a machine made in such a way that it expresses words, even that it expresses some words relevant to some physical actions which bring about some change in its organs (for example, if one touches it in some spot, the machine asks what it is that one wants to say to it; if in another spot, it cries that one has hurt it, and things like that), but one cannot imagine a machine that arranges words in various ways to reply to the sense of everything said in its presence, as the most stupid human beings are capable of doing. The second test is that, although these machines might do several things as well or perhaps better than we do, they are inevitably lacking in some other, through which we discover that they act, not by knowledge, but only by the arrangement of their organs. For, whereas reason is a universal instrument which can serve in all sorts of encounters, these organs need some particular arrangement for each particular action. As a result of that, it is morally impossible that there is in a machine's organs sufficient variety to act in all the events of our lives in the same way that our reason empowers us to act ". This is not an argument, this is an ad machinam fallacy ${ }^{5}$.

In another contemporary of Descartes, Blaise Pascal, we can find another emotional argument when he talks about his extraordinary arithmetical machine, the Pascaline: "the arithmetical machine produces effects which approach nearer to thought than all the actions of animals. But it does nothing which would enable us to attribute will to it, as to the animals". They feared the arguments: if the Universe is a machine and we are also machines, artificial machines could be something threatening to humans: faster, stronger and better than us in several ways, they seemed to be the superior being.

\footnotetext{
${ }^{2}$ Brooks (1991).

${ }^{3}$ Vallverdú (2005).

${ }^{4} \mathrm{http://wordnet.princeton.edu/perl/webwn?s=intelligence.}$

5 The neologism is mine. Ad machinam: fallacy that express the irrational or non-argued attitude against machines and their habilities, including intelligence, creativity or intentionality.

${ }^{6}$ Thoghts, Chapter VI, § 340 .
} 
The negative Utopia Erewhon, of Samuel Butler, express these feelings': 'There is no security'-to quote his own words-'against the ultimate development of mechanical consciousness, in the fact of machines possessing little consciousness now. A mollusc has not much consciousness. Reflect upon the extraordinary advance which machines have made during the last few hundred years, and note how slowly the animal and vegetable kingdoms are advancing. The more highly organized machines are creatures not so much of yesterday as of the last five minutes, so to speak, in comparison with past time. Assume for the sake of argument that conscious beings have existed for some twenty million years: see what strides machines have made in the last thousand! May not the world last twenty million years longer? If so, what will they not in the end become? Is it not safer to nip the mischief in the bud and to forbid them further progress? 'But who can say that the vapour engine has not a kind of consciousness? Where does consciousness begin, and where end? Who can draw the line? Who can draw any line? Is not everything interwoven with everything? Is not machinery linked with animal life in an infinite variety of ways? The shell of a hen's egg is made of a delicate white ware and is a machine as much as an egg-cup is; the shell is a device for holding the egg as much as the egg-cup for holding the shell: both are phases of the same function; the hen makes the shell in her inside, but it is pure pottery. She makes her nest outside of herself for convenience' sake, but the nest is not more of a machine than the egg-shell is. A "machine" is only a "device." '

And at the end of XIX ${ }^{\text {th }}$ century Walt Withman wrote in Song of Myself, $\S 31$ : "I believe a leaf of grass is no less than the journey work of the stars,/And the pismire is equally perfect, and a grain of sand, and the egg of the wren, /And the tree-toad is a chef-d'oeuvre for the highest,/And the running blackberry would adorn the parlors of heaven,/And the narrowest hinge in my hand puts to scorn all machinery,/And the cow crunching with depress'd head surpasses any statue,/And a mouse is miracle enough to stagger sextillions of infidels."

But let us to look to arguments dedicated to contemporary Al. From the seminal Dreyfus RAND paper against $\mathrm{Al}$ ( $\mathrm{Al}$ as $A / \mathrm{lchemy})^{8}$ have appeared a big amount of critics against $\mathrm{Al}$ efforts. There are different controversial concepts inside $A \mathrm{I}$ in relation to human mind: creativity, emotions, free will, thinking (Chinese room John Searle (1980); Dreyfus (1972, 1992)), biological base (neurophilosophy by P.S. Churchland), uniqueness of human culture (human still believe in Scala naturalis), consciousness,...9

We can find those questions not only in the philosophy of science but also in other scientific disciplines or also in society. There is a lot of fear to machines in contemporary popular art: Matrix (Wachowsky brothers), Metropolis (Fritz Lang), Blade Runner (Ridley Scott),...

They seem to be a fear reaction to a still remote fact, that is, intelligent machines like us. The rhetoric of philosophical argumentation disables them to realize of the meaning and deepness of $\mathrm{Al}$ implementation on contemporary scientific processes. Philosophers are fighting with a chimera, while Al is more and more crucially embedded on scientific practices and discourses. It is true that exists controversies among Al researchers. There are basically two main approaches to do research about Al, which we can summarize as top down and bottom up approaches:

i. Top Down: symbol system hypothesis (Douglas Lenat, Herbert Simon). The top down approach constitutes the classical model. It works with symbol systems, which represent entities in the world. A reasoning engine operates in a domain independent way on the symbols. SHRDLU (Winograd), Cyc (Douglas Lenat) or expert systems are examples of it.

ii. Bottom Up: physical grounding hypothesis (situated activity, situated embodiment, connexionism). By the other side, the bottom up approach (leaded by Rodney Brooks), is based on the physical grounding hypothesis. Here, the system is connected to the world via a set of sensors and the engine extracts all its knowledge from these physical sensors. Brooks talks about "intelligence without representation": complex intelligent systems will emerge as a result or complex interactive and independent machines.

But we don't need perfect models and explanations of the world to interact with it: First steam machines worked previously to the development of the thermodynamic laws (and then, that knowledge

\footnotetext{
${ }^{7}$ Chapter XXIII.

${ }^{8}$ And later books Freyfus (1972), (1992).

${ }^{9}$ See Dodig-Crnkovic (2003), section 3.
} 
improved the way to construct them). Besides, models that fit well are not necessarily correct: Ptolemaic astronomy (geocentric theory, circular and regular planetary movements, epicycles, deferents...), Hippochratic medicine (4 humours), Lavoisier's correct ideas about spontaneous generation (in relation to an evolutionary theory) are examples of that point.

Perhaps the aim of science, and Al science, is solving problems (Larry Laudan, Progress and its problems, 1978). Both approaches (bottom up-top down, and collateral results) have succeeded, in several ways. Both approaches, bottom up/top down, satisfy several necessities of scientific research and human necessities.

\section{Al implementation and the new in silico science.}

$\mathrm{Al}$ and computer sciences are been creating a new kind of making science, that we can call in silico science. Historically, science started as an observational process, an in vivo science. At the end on Middle Ages and during Renaissance science become a laboratory-experimental practice, an in vitro science. At the end of $X X^{\text {th }}$ century, science is made with computers and Al systems, that is, an in silico science.

Machines are embedded on our bodies and practices (Clark, 2003), they are an extension of ourselves (Humphreys, 2004). Besides, this new e-science ${ }^{10}$, has several characteristics computationally related to 'information':

\begin{tabular}{|c|c|}
\hline Processes & Facts \\
\hline Creation/Discovery & $\begin{array}{l}\text { Data Tsunami: Petabytes of data } \\
\text { Virtual Instruments } \\
\text { Ontologies } \\
\text { Artificial Intelligence and Expert Systems }\end{array}$ \\
\hline $\begin{array}{l}\text { Management: search- } \\
\text { access-movement- } \\
\text { manipulation-mining }\end{array}$ & $\begin{array}{c}\text { Databases: } \\
\text { Complex, hierarchical, dynamic, inconsistent. } \\
\text { Software } \\
\text { Middleware }\end{array}$ \\
\hline Understanding & $\begin{array}{c}\text { Computerized Modelization } \\
\text { Imaging } \\
\text { Information integration }\end{array}$ \\
\hline Evaluation & $\begin{array}{l}\text { Computational, open. } \\
\text { Verification- Validation (V\&V) }\end{array}$ \\
\hline Communication & Electronic open access journals: PloS. \\
\hline Work strategies & $\begin{array}{c}\text { Delocalized } \\
\text { Network } \\
\text { Cooperative } \\
\text { Dynamical } \\
\text { Interoperability } \\
\text { Spatially distributed cognition \& computing }\end{array}$ \\
\hline Funding & $\begin{array}{l}\text { Public-private (HGP-Celera, Roslin-PPT....) } \\
\text { symbiosis. }\end{array}$ \\
\hline Control & Beyond national and single reviewer control. \\
\hline
\end{tabular}

A new kind of 'matter', information, is constraining scientific methodologies and the ways by which scientists create knowledge. And Al techniques embedded on computational tools are something indispensable throughout the all process ${ }^{11}$. Al is being successfully implemented on scientific reasoning by several ways. Their results are not simple instruments, but fundamental parts or scientific research.

\footnotetext{
${ }^{10}$ Hendler (2003).

${ }^{11}$ Barrera, J. et al (2004).
} 
Sometimes they are the arms, eyes, ears or legs of scientists, but sometimes they are also their brains ${ }^{12}$. We don't need a battle between software and wetware, but a collaborative enterprise for the acquisition of knowledge.

But $\mathrm{Al}$ is not only a helping tool for human beings: it can be also an active subject of knowledge acquisition and discovery (Valdés-Pérez, 1995; 1999; De Jong \& Rip, 1997; Alai, 2004). We can talk of the automation of proof $^{13}$.

In my paper I shall develop the rational-framing approach to defend Al successes and show its broad implementation in scientific reasoning. We shall define the terms:

(a) rational: consistent with or based on using reason, where 'reason' is understanding and capacity to predict future situations. The use of the rational methods of inquiry, logic, and evidence in developing knowledge and testing claims to truth.

(b) framework: a structure supporting or containing something. We will demonstrate that $\mathrm{Al}$ results are at the same time supporting scientific research and are also the research itself. Computations and robotics are not only tools for science: they are true science. Without them, science of $21^{\text {st }}$ century would be not the same. Al products are embedded on scientific activities.

So, beyond philosophical academic arguments against or in favour of Al, there is a rational and framework space in which we can analyze and talk about the results and impact or Artificial Intelligence on several scientific disciplines. I will show some areas in which Al research has contributed to knowledge development:

1. Rational areas:

- Nobel laureate Lars Onsager use of a method called 'computational intractability' contributed to prove that the much-studied Ising model cannot be extended to three dimensions. That problem cannot be solved in humanly feasible time.

- In 1996, a powerful automated reasoning software solved the "Proof of Robbins Conjecture" (1930s), the demonstration that a particular set of three equations was powerful enough to capture all the laws of Boolean algebra.

- The second Asilomar meeting confirmed that automatically generated predictions with PredictProtein), a special intelligent software, were highly valuable to research and discovery ${ }^{14}$.

- High-performance computing has become crucial in many fields, like materials research, climate prediction or bioinformatics. This one, bioinformatics, is perhaps the most powerful scientific discipline in our days.

- Expert systems like Dendral (mass spectography), Mechem (chemistry) Maxima (mathematics), Internist (medicine) or Mycin (medicine), have improved specialized knowledge.

\section{Framework areas:}

- Recently (when I writing this words), the European Space Agency's (ESA's) Huygens probe has descended through the atmosphere of Saturn's moon Titan. For several reasons (budget, technical difficulties,...), our main input of planetary research and good astronomical data comes from robots like Huygens probe or Hubble telescope.

- There also scientist robots like Robot Scientist (Ross King, University of Wales) who can contribute to make science cheaper, faster and more precise.

- Al systems present inside software, distributed computing ${ }^{15}$ and middleware enables work efficiently with databases and huge amount of data.

4 Humans and Machines: extensional symbiosis and technothoughts.

\footnotetext{
${ }^{12}$ Long et al (2003).

${ }^{13}$ Mackenzie (1995).

${ }^{14}$ Stormo (2000) provide a brief history of the development and application of computer algorithms for the analysis and prediction of DNA binding sites.

${ }^{15}$ See 'Special Section' on Distributed Computing in Science, Vol 308, 6 MAY 2005:809-824.
} 
It is a fact that actually there is a strong connexion between humans and machines. But if we consider tools like first man-made machines, humanity (as homo faber) is linked to artificial technological extensions from ancient times.

Nevertheless, last decades have changed completely our relationship with technology: internet, computation, bionics or genomics are some of the deep changes of $\mathrm{XXI}^{\text {st }}$ century human life. From war efforts has appeared a Big Science ${ }^{16}$ that produce huge amount of data. Pursuing better knowledge about the world we use more machines not only to produce data but also to understand them. As example, the Large Hadron Collider (CERN, Geneve), produce every year 15 petabytes (15 Gigabytes' million!). Just to classify, analyze and use them it has been required to create supercomputers and computational grid like LHC Computer Grid $^{17}$. That quantity-of-data issue requires new ways to make and organize scientific practices: supercomputers, grids, distributed computing, specific software and middleware and, basically, more efficient and visual ways to interact with information. This is one of the key points to understand contemporary relationships between humans and machines: usability of scientific data. This is not a recent issue: new symbolic language for chemistry changed their historical development ${ }^{18}$. We must remember that approximately $60 \%$ of brain's sensory inputs come from vision ${ }^{19}$. But the iconic-propositional presentation of data is not possible (from an epistemic point of view) when we must assimilate millions of data points, as it happens in astrophysics, nuclear physics or genomics. Therefore, 3D computational techniques are something necessary for the evolution of new science or creation of new field like 'anatomics' ${ }^{20}$. And they are also extremely useful for a better training of new scientists ${ }^{21}$. Contemporary sciences are more quantitative $\mathrm{e}^{22}$ and use more models by computational simulations ${ }^{23}$.

\section{$5 \quad$ Talking about 'technotoughts'?}

Finally, We must think about other contributions of computer science and its meaning for daily activity and new ways of thinking: hypertextual forms ${ }^{24}$ (webcrawlers, websites, hypertext, e-mail, chats, cyberspace forums, blogs), computer-aided education (Tarksi's World, Hyperproof, hypermedia), online databases, digital media or leisure spaces (games, some of them with improving skills useful for professional training: from chess to Commandos $3^{25}$ ). As I will defend, we are assisting to a computerization of science (by Al results) and life (virtual communities, hacktivism, e-democracy ${ }^{26}$, flash mobs, book-crossing,...). And we can find as first time in human history, direct cooperation between scientists and civil society through distributed computation (seti@home, folding@home, genome@home, Einstein@home ...) and new models of science management joining together expert and local knowledge.

The efforts of computer and Al scientists are changing completely our societies, our science and our own thoughts. Thanks to them, we have a new philosophical approach to the world ${ }^{27}$, with an increasingly machine empowerment in science and society. More than ever, we have technotoughts.

Technothoughts are 'human' thoughts that have a strong relationship with machines, some of them produced by Al research. Beyond classical Al controversies, machines (perhaps some of them 'intelligent', it depends on the previous definition) are changing not only our thoughts, but also our bodies and our ways of thinking. Exist at least three ways to analyze that relationship: (i) machines which help us to think, (ii) thinking machines and (iii) machines embedded in our thoughts. The computer revolution (including hardware/software/middleware, robotics and $\mathrm{Al}$ ), the informational turn and the ICT (Information and Communication Technologies $)^{28}$ have generated those new kinds of thoughts, that is, technothoughts.

\footnotetext{
${ }^{16}$ Galison \& Hevly (1994).

$17 \mathrm{http}: / /$ lcg.web.cern.ch/LCG. There is also a big effort in the development of specific software and middleware to enable distributed work. Human Genome Project is another with great amounts of data produced every year.

${ }^{18}$ Latour (1986), Giere \& Moffat (2003).

${ }^{19}$ Humphreys (2004): 112. Rapp (2003).

${ }^{20}$ Bard (2005).

${ }^{21}$ Wickware (2000), says, p. 683: "the ideal next-generation biologists should develop both wet-lab experise and software-writing ability". Also Baldi \& Brunak (2001), Lillehaug \& Lajoie (1998).

${ }^{22}$ Richardson (1997).

${ }^{23}$ Casti (1997), Keller (2000), Humphreys (2002), Winsberg (2003).

${ }^{24}$ Rouet (1996). Kolb (1995).

${ }^{25}$ Read the astonishing paper of Miskry et al (2002).

${ }^{26}$ Sunstein (2001).

${ }^{27}$ Bynum \& Moor (1998), Thagard (1993), Sloman (1978). Specially, a Philosophy of Information Floridi (2001, 2002, 2003).

${ }^{28}$ The Network Society, Castells (1996).
} 
Machines are more human (3D, friendly ontologies, sociability ${ }^{29}$, emotional outputs ${ }^{30} \ldots$ ) to help humans to understand the results if the huge amount of data that provide us the same machines. It is a symbiotic relationship between humans and machines. We have a new e-science for the humanity. Those new mechanisms occupy and maintain our own mental spaces (how could man write things B.C., that is, before computers?). We are cyborgs, but in an extended point of view e-cyborgs. And those new forms of make science and to be human require to introducing new values to our understanding models (new concepts about 'rationality', 'emotions', 'proof', 'demonstration'...). Perhaps we need a philosophy of artificial intelligence ${ }^{31}$, or a philosophy of a new e-intelligence dominated by technothoughts.

\section{References}

Alai, M. (2004) “A.I., Scientific Discovery and Realism", Minds and Machines, Vol. 14. pp. 21-42.

Baldi, P. \& Brunak, S. (2001), Bioinformatics: the Machine Learning Approach, Cambridge, MA: MIT Press.

Bard, Jonathan B.L. (2005) "Anatomics: the intersection of anatomy and bioinformatics", J. Anat, 206, pp. 1-16.

Barrera, J. et al (2004) "An environment for knowledge discovery in biology", Computers in Biology and Medicine, Vol. 34. pp. $427-447$.

Breazeal, C. (2002) Designing Sociable Robots, Cambridge, MA: The MIT Press.

Brooks, R. A. (1990) "Elephants Don't Play Chess", Robotics and Autonomous Systems, Vol. 6. pp. 3-15

Brooks, R. A. (1991) "Intelligence without representation", Artificial Intelligence, Vol. 47. pp. 139-159.

Bynum, T. W. \& Moor, J.H. (1998) The Digital Phoenix. How Computers Are Changing Philosophy, UK: Blackwell Publishers.

Castells, M. (1996) The Rise of the Network Society, Oxford: Blackwell.

Casti, J. L. (1997) Would-be worlds. How simulation is changing the frontiers of Science, New York: John Wilery \& Sons.

Clark, A., (2003) Natural-born cyborgs. Minds, technologies, and the future of human intelligence. USA: Oxford University Press.

De Jong, H. \& Rip, A. (1997) "The computer revolution in science: steps towards the realization of computer-supported discovery environments”, Artificial Intelligence, Vol. 91. pp. 225-256.

Dodig-Crnkovic, G. (2003) "Shifting the Paradigm of Philosophy of Science: Philosophy of Information and a New

Renaissance", Minds and Machines, Vol. 13. pp. 521-536.

Dreyfus, H. L. (1972) What computers can't do, Cambridge (MA): The MIT Press.

Dreyfus, H.t L. (1992, $3^{\text {rd }}$ reprinted) What computers still can't do, Cambridge (MA): The MIT Press.

Floridi, L. (2001) "Information Ethics: An Environmental Approach to the Digital Divide", Philosophy in the Contemporary World, Vol. 9, No. 1 (Spring-Summer).

Floridi, L. (2002) "What is the Philosophy of Information?", Metaphilosophy, Vol. 33, No. 1/2. pp. 123-145.

Floridi, L. (2003) "Two Approaches to the Philosophy of Information",Minds and Machines, Vol. 13. pp. 459-469.

Galison, P. L. \& Hevly, B. (eds.) (1994) Big Science: The Growth of Large-Scale Research, USA: Stanford University Press.

Giere, R.N. \& Moffatt, B. (2003) "Distributed Cognition:Where the Cognitive and the Social Merge”, Social Studies of Science, Vol. 33, No. 2. pp. 1-10.

Hendler, J. (2003, January 24th) "Science and the Semantic Web", Science, Vol. 299. pp. 520-521.

Humphreys, P. (2002) "Computational Models", Philosophy of Science, Vol. 69. pp. S1-S11.

Humphreys, P. (2004) Extending Ourselves. Computational Science, Empiricism and Scientitic Method, USA: Oxford University Press.

Hutchins, E (1995) Cognition in the Wild, Cambridge, MA: MIT Press.

Keller, E. F. (2000) "Models Of and Models For: Theory and Practice In Contemporary Biology", Philosophy of Science, Vol. 67. pp. S72-S86.

Kolb, D. (1994) Socrates in the Labyrinth: Hypertext, Argument, Philosophy., Watertown, MA, Eastgate Systems.

Kurzweil, R. (1990) The Age of Intelligent Machines, Cambridge, MA.: $\quad$ MIT Press.

Latour, B. (1986) "Visualization and Cognition: Thinking with Eyes and Hands", Knowledge and Society, Vol. 6. pp. 1-40.

\footnotetext{
${ }^{29}$ Picard (1997).

${ }^{30}$ Breazeal (2002).

${ }^{31}$ Schiaffonati (2003)
} 
Lillehaug, Svein-Ivar \& Lajoie, Susanne P. (1998) "Al in medical education - another grand challenge for medical informatics", Artificial Intelligence in Medicine, Vol. 12. pp. 197-225.

Long, M et al (2003) "Origin of new genes: evidence from experimental and computational analyses”, Genetika, Vol. 118. pp. 171182.

Mackenzie, Donald (1995) "The Automation of Proof: A Historical and Sociological Exploration", IEEE Annals of the History of Computing, Vol. 17, No. 3. pp. 7-29.

Miskry, Tariq et al (2002) "If you're no good at computer games, don't operate endoscopically!", Gynaecological Endoscopy,

Vol. 11. pp. 345-347.

Picard, R.W. (1997) Affective Computing, Cambridge, MA: The MIT Press.

Rapp, David N. et al (2003) "The impact of digital libraries on cognitive processes: psychological issues of hypermedia”, Computers in human behavior, Vol. 19. pp. 609-628.

Richardson, Robert C. (1997) "Natural and Artificial Complexity", Philosophy of Science, Vol. 64. pp. S255-S267.

Rouet, Jean-François (1996) Hypertext and Cognition, USA: Lawrence Erlbaum Associates, Inc.

Schiaffonati, Viola (2003) “A Framework for the Foundation of the Philosophy of Artificial Intelligence”, Minds and Machines, Vol. 13. pp. 537:552.

Searle, John (1980) “Minds, Brains and Programs”, Behavioral and Brain Sciences, Vol. 3, No. 3. pp. 417-458.

Simon, Herbert A. (1995) "Artificial Intelligence: an empirical science”, Artificial Intelligence, Vol. 77. pp. 95-127.

Sloman, Aaron (1978) The Computer Revolution in Philosophy, Cambridge (MA): Harvard University Press.

Stormo, Gary D. (2000) “DNA binding sites: representation and discovery”, Bioinformatics, Vol.16, No. 1. pp. 16-23.

Sunstein, C. R. (2001) Republic.Com, Princeton, N.J.:Princeton University Press.

Thagard, Paul (1993) Computational Philosophy of Science, Cambridge (MA): MIT Press.

Valdés-Pérez, Raúl E. (1995) "Machine discovery in chemistry: new results", Artificial Intelligence, Vol. 74. pp. $191-201$.

Valdés-Pérez, Raúl E. (1999) "Principles of human-computer collaboration for knowledge discovery in science", Artificial Intelligence, Vol. 107. pp. 335-246.

Vallverdú, Jordi (2005) "Robots: la frontera de un nuevo arte”, Cuadernos del Minotauro, Vol. I, No. 1, Junio. pp. 21-30.

Wickware, Potter (2000) "Next-generation biologists must straddle computation and biology”, Nature, Vol. 404. pp. 683-684.

Winsberg, Eric (2003) “Simulated Experiments: Methodology for a Virtual World”, Philosophy of Science, Vol. 70. pp. $105-125$. 